\title{
A STUDY ON DIFFERENT FOREIGN BODIES PRESENTING IN NASAL CAVITY IN KADAPA DISTRICT, ANDHRA PRADESH - A TWO YEARS EXPERIENCE
}

\author{
G. Sreenivasulu 1 , G. Sudhindra ${ }^{2}$
}

${ }^{1}$ Assistant Professor, Department of ENT, Rajiv Gandhi Institute of Medical Sciences, Kadapa.

2Postgraduate Student, Department of ENT, Rajiv Gandhi Institute of Medical Sciences, Kadapa.

\section{ABSTRACT}

\section{BACKGROUND}

The aim of this study was to determine the common presentations and management outcomes in cases with nasal foreign bodies.

\section{MATERIALS AND METHODS}

A retrospective study was carried out over two years from January 2013 to December 2015. The total number of patients were 200; maximum age was 9 years. Patient biodata, clinical presentation, type of foreign body and management outcome were obtained and analysed from the medical records of Rajiv Gandhi Institute of Medical Sciences, Kadapa.

\section{RESULTS}

Of the total 200 patients, $62 \%$ were male and $38 \%$ were female. The most frequent age at which nasal foreign bodies were found in the age bracket of 0-3 years (48\%) and the least frequent age bracket was 7-9 years (36\%). Most patients had foul smelling nasal discharge, nasal bleed or asymptomatic; vegetable seeds (32\%) were the most common foreign bodies, followed by slate pencil $(19 \%)$ and stones $(18 \%)$, and batteries $(2.5 \%)$ were the least common type. In most cases (58\%), the foreign body had been inserted into the right nostril; $40 \%$ were inserted into the left nostril and $2 \%$ were bilateral. Most of the foreign bodies were removed locally, few required general anaesthesia.

\section{CONCLUSION}

Most common age group noted is less than three years of age and males were most commonly affected. Patients mainly present wi th unilateral foul smelling nasal discharge.

\section{KEYWORDS}

Foreign Body, Nose.

HOW TO CITE THIS ARTICLE: Sreenivasulu G, Sudhindra G. A study on different foreign bodies presenting in nasal cavity in Kadapa district, Andhra Pradesh - A two years experience. J. Evolution Med. Dent. Sci. 2016;5(103):7520-7522, DOI: 10.14260/Jemds/2016/1702

\section{BACKGROUND}

Foreign bodies in the nose are common in children.1,2 as compared to other regions i.e., foreign body in ear, oesophagus and bronchus. Foreign bodies in nose are relatively easily removed in an office based procedure; if the foreign body is a battery or is impacted and having long duration history and if the child is uncooperative; however, special precautions have to be taken. In addition, if the child is uncooperative, general anaesthesia is usually required to prevent complications. Batteries are the type of foreign bodies most commonly associated with early complications despite improvements in product safety. Due to their small size, batteries can easily be inserted into various orifices such as nose, ear or mouth. ${ }^{3}$ There are various routes via which foreign bodies enter the nose, the anterior nares being the commonest. Nasal surgery and penetrating wounds have been reported as causes of nasal foreign body. ${ }^{4}$ Foreign bodies may be organic or inorganic, and

Financial or Other, Competing Interest: None.

Submission 19-11-2016, Peer Review 13-12-2016,

Acceptance 19-12-2016, Published 26-12-2016.

Corresponding Author:

Dr. G. Sreenivasulu

Assistant Professor

Department of ENT,

Rajiv Gandhi Institute of Medical Sciences,

Kadapa.

E-mail: seenu1gosi@gmail.com

DOI: $10.14260 /$ jemds/2016/1702 principally affect children, especially aged between 2 and 3 years of age. ${ }^{5}$ Inorganic materials are typically plastic, ${ }^{6}$ such as beads or buttons, or stones, paper or small parts from toys; they are often asymptomatic and are usually discovered incidentally.

On the other hand, organic foreign bodies may produce earlier symptoms because they tend to be more irritating to the nasal mucosa. ${ }^{7}$ Nasal foreign bodies may be in any part of the nasal fossa, but the commonest location is just anterior to the middle turbinate or below the inferior turbinate. ${ }^{8}$ Removal of the nasal foreign body depends on its site and size and on the cooperation of the child. Different methods of foreign body removal have been reported, ${ }^{9}$ and depend on the preference of the centre. Positive diagnosis is often easy, but may be delayed by the context, type of foreign body or non-specificity of the symptomatology. Early diagnosis can avoid potentially serious complications related to the nature of the foreign body itself or to chronicisation of the resultant irritation with a real risk of super infection.

\section{MATERIALS AND METHODS}

This is a retrospective study of the cases involving foreign bodies in the nose which presented as emergency and outpatient department in our institute. Patient biodata, clinical presentation, type of treatment and complications following removal were assessed. 


\section{RESULTS}

In the present study, the most common paediatric age group involved was less than 3 years age group (48\%) in which males (65\%) were more than females (34.3\%) followed by 4 to 6 years age group $(68 \%)$ in which males $(66.1 \%)$ were more compared to female children (33.8), and the least common was 7 to 9 years (36\%). The sex ratio showed female predominance $(58.33 \%)$ in this group compared to males (41.67\%). The most frequent presentations were foul smelling nasal discharge, epistaxis, nasal obstruction. Initially, most of them presented to paediatric outpatient department as foul smelling unilateral nasal discharge. The most common type of foreign body was vegetable seeds (32\%), followed by slate pencils (19\%), stones (18\%) and the least type being button cells (5\%). In majority of patients (58\%), the foreign body had been inserted in the right nostril, compared to $40 \%$ in the left, with bilateral insertion in $2 \%$ of cases. Most of the cases were presented immediately within 3 days, but few cases presented with longstanding history of one month presenting with foul smelling discharge and epistaxis. Most of the cases were managed as outpatient procedure, but very few cases as impacted foreign bodies, button cells and uncooperative children underwent removal under general anaesthesia. Postoperatively, most cases were free of complications (93\%). A few complications were; however, noted: septal perforation $(4.70 \%)$ and bleeding (2.30\%).

\section{Sex Distribution}

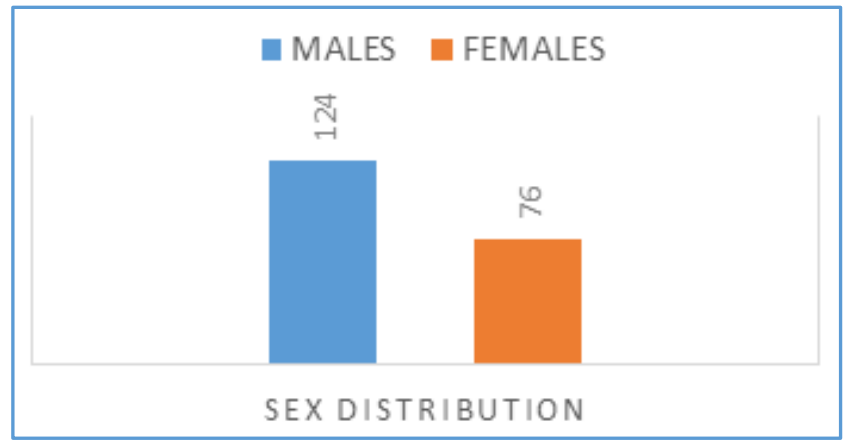

Age and Sex Distribution of Patients

\begin{tabular}{|c|c|c|c|c|}
\hline Age Group & Total & $\mathbf{( \% )}$ & Male & Female \\
\hline 0-3 Years & 96 & 48 & $63(65 \%)$ & $33(34.3 \%)$ \\
\hline 4-6 Years & 68 & 34 & $45(66.1 \%)$ & $23(33.8 \%)$ \\
\hline 7-9 Years & 36 & 18 & $15(41.67 \%)$ & $21(58.3 \%)$ \\
\hline
\end{tabular}

\begin{tabular}{|c|c|c|}
\hline $\begin{array}{c}\text { Nature of } \\
\text { Foreign Body }\end{array}$ & No. of Cases & Percentage (\%) \\
\hline Vegetable seeds & 64 & 32 \\
\hline Plastic beads & 34 & 16.5 \\
\hline Paper & 24 & 12 \\
\hline Slate pencil & 38 & 19 \\
\hline Stone & 36 & 18 \\
\hline Button cell & 5 & 2.5 \\
\hline
\end{tabular}

Categories of Foreign Bodies Presenting with distribution according to the Side of Nostril

\section{SIDE OF NOSTRIL}

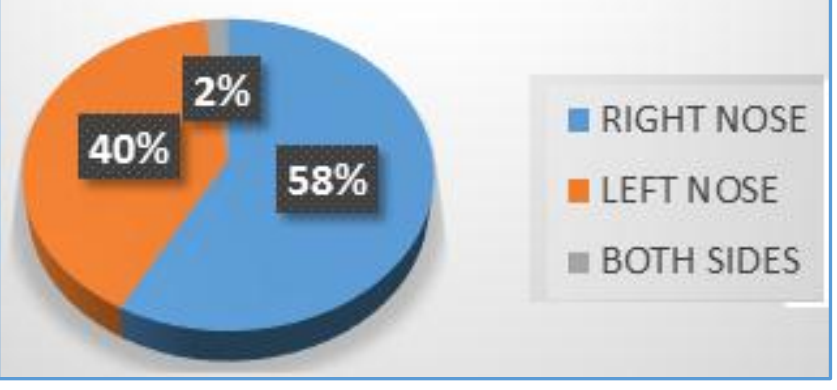

\section{DISCUSSION}

Nasal foreign bodies are common problems in the paediatric age group, ${ }^{1,2}$ encountered in our daily practice, especially in children aged between 2 and 3 years. ${ }^{3}$ Quite often, they can be easily removed; however, unsuccessful attempts at removal may cause bleeding, pain or local injury, hindering further attempts. ${ }^{9}$ A number of factors have been associated with the success of foreign body removal, including duration of foreign body residence, foreign body characteristics (size, shape and texture), patient cooperation during removal, trauma to the nasal cavity, ability to visualise the foreign body and surrounding structures, available equipment and the skill of the attending physician. ${ }^{1}$ In the present series, the most common complaint was foul smelling odour. In a related study, $75 \%$ of patients presented with alleged nasal foreign body insertion, which was usually confirmed on examination. ${ }^{10}$ Thus, such history is important and should never be overlooked. Other presentations included bleeding (4.65\%) and nasal obstruction (2.33\%). In the present series, the most frequent age group was less than 3 years age group followed by 4 to 6 years group and the least frequent 7 to 9 years, which is similar to other studies, in which most patients were under 5 years of age.5,11,12 The predominance of this age group is unsurprising, children of this age being by nature inquisitive and willing to explore their body cavities, especially the nose and ears. The male predominance in the present series is in agreement with other reports.5,11 In our series, fewer patients presented within 24 hours, while more presented within 1 week. This is similar to a study elsewhere, in which just under half the patients presented within 24 hours. ${ }^{13}$ In contrast, in another study, it was reported that the majority presented within 24 hours. ${ }^{5}$ Predominantly, late presentation is due to the fact that nasal foreign bodies, especially when inert, usually do not interfere with function. With time, however, normal nasal clearance is interrupted and super infection occurs. More than $10 \%$ of patients in our study presented months after foreign body insertion, with foul smelling nasal discharge. In another study, only about 3\% presented months after insertion. ${ }^{13}$ The most common foreign body found in our study was vegetable seed, followed by slate pencils and stones, and the least common were button cells; these results are similar to those of Ogunleye and Sogebi12, where grains or seeds were the commonest, but in contrast to studies in Europe. ${ }^{14}$ and elsewhere. ${ }^{15}$, the right nostril was the commonest site of foreign body insertion in our series. This is not surprising since most children are right-handed. 
The finding of $2 \%$ bilateral insertion is similar to other reports. ${ }^{13,14,16}$ This implied that the cases managed in our department were mostly difficult and complicated, with a large proportion managed elsewhere. Only about $40 \%$ of the patients presenting to our department were managed according to the published guidelines for nasal foreign body removal.5,17 In a few patients (about 5\%), the foreign body was dislodged spontaneously and uneventfully before any intervention. The few postoperative complications comprised septal perforation (4.7\%) and bleeding (2.3\%). Septal perforation occurred when the foreign body was a battery, due to extensive liquefying necrosis of surrounding tissues following leakage of alkaline electrolyte solution from the battery rather than to the procedure itself. Other factors related to complications in nasal foreign body are foreign body size and shape, unskilled attempts at removal and the length of time the foreign body remains lodged in the nose.14,17 Early referral to a specialist is recommended if there is a history of prolonged unilateral or bilateral (in case of bilateral nasal foreign body) nasal discharge, the patient is very uncooperative or agitated, the foreign body is posteriorly located, lack of experience and/or confidence on the part of the attending physician, or unavailability of proper basic equipment. Foreign body aspiration in the paediatric age group is a common phenomenon. However, in our series there were no cases of foreign body aspiration into the larynx or bronchus. Gandhi et al[18] reported that children aged between 1 and 3 years show the highest incidence of foreign body aspiration.

\section{CONCLUSION}

Nasal foreign bodies are an accident frequently encountered in medical practice, especially in young children $(<3$ years of age). They arise from the child's interaction with the environment. The accident is generally known to the family, so that treatment is not delayed and sequelae and complications are minimised. Some cases; however, are serious and require emergency extraction. Extraction techniques vary with the kind of object. The contralateral cavity and the ears should also always be examined. The best treatment remains prevention.

\section{REFERENCES}

1. Botma M, Bader R, Kubba H. 'A parent's kiss': evaluating an unusual method for removing nasal foreign bodies in children. J Laryngol Otol 2000;114(8):598-600.

2. Kadish HA, Corneli HM. Removal of nasal foreign bodies in paediatric population. Am J Emerg Med 1997;15(1):54-6.
3. Loh WS, Leong JL, Tan HK. Hazardous foreign bodies: complications and management of button batteries in nose. Ann Rhinol Laryngol 2003;112(4):379-83.

4. Walby AP. Foreign bodies in the ear or nose. In: Adam DA, Ginnamond MJ, editors. Scott-Brown's paediatric otolaryngology. $6^{\text {th }}$ ed. Oxford: Butterworth-Heinemann 1997:[6/14/1-6/14/6].

5. Roland NJ, McRae RDR, McCombe AW. Key topics in otolaryngology and head and neck surgery. $3^{\text {rd }}$ ed. Oxford: BIOS Scientific Publishers 2005:104.

6. Ngo A, Ng KC, Sim TP. Otolaryngeal foreign bodies in children presenting to the emergency department. Singapore Med J 2005;46(4):172-8.

7. Backlin SA. Positive pressure technique for nasal foreign body removal in children. Ann Emerg Med 1995;25(4):554-5.

8. Baluyot ST. Foreign bodies in the nasal cavity. In: Paparella MM, Shumrick DA, editors. Otolaryngology, Vol 3. $2^{\text {nd }}$ ed. Philadelphia, PA: W.B. Saunders 1980:2009-16.

9. Kiger JR, Brenkert TE, Losek JD. Nasal foreign body removal in children. Pediatr Emerg Care 2008;24(11):785-92.

10. Chai KC, Tang IP, Tan TY, et al. A review of ear, nose and throat foreign bodies in Sarawak general hospital: a fiveyear experience. Med J Malaysia 2012;67(1):17-20.

11. Cohen HA, Goldberg E, Horev Z. Removal of nasal foreign bodies in children. Clin Pediatr (Phila) 1993;32(3):192.

12. Ogunleye AO, Sogebi OA. Nasal foreign body in African children. Afr J Med Sci 2004;33(3):225-8.

13. Afolabi OA, Suleiman AO, Aremu SK, et al. An audit of paediatric nasal foreign bodies in Ilorin, Nigeria. SAJCH 2009;3(2):64-7.

14. Francois M, Harioui R, Narcy P. Nasal foreign bodies in children. Eur Arch Otorhinolaryngol 1998;255(3):132-4.

15. Wada I, Miskima H, Hida T, et al. Nasal foreign bodies in 299 cases. Nippon Jibiinkoka Gakkai Kaiho 2000;103(11):1212-7.

16. Muhammad H, Zakirullah, Inayatullah. Foreign body nose in children: a common problem with social roots. Abasyn Univ J Soc Sci 2009;2(1):22-5.

17. Kalan A, Tariq M. Foreign bodies in the nasal cavities: a comprehensive review of the aetiology, diagnostic pointers, and therapeutic measures. Postgrad Med J 2000;76(898):484-7.

18. Gandhi R, Jain A, Agarwal R, et al. Tracheobronchial foreign bodies-a seven years review. J Anesth Clin Pharmacology 2007;23(1):69-74. 